\title{
KONDISI REAL PEMBELAJARAN DI KELAS
}

\author{
Casmudi \\ Universitas Balikpapan \\ Pos-el: casmudi@uniba.bpn.ac.id
}

\begin{abstract}
ABSTRAK
Tujuan penelitian ini untuk mengetahui kondisi real pembelajaran dalam kelas. Penelitian dilakukan pada 23 sekolah yang terdiri dari SMA dan SMK di Balikpapan, penelitian yang dilakukan yaitu penelitian Tindakan Sekolah. Kondisi real yang ada pada sekolah SMA dan SMK di Balikpapan, fasilitas tempat duduk dan meja di kelas sudah cukup menunjang anda untuk belajar, luas ruangan belajaran anda cukup memadai, sehingga leluasa belajar, fasilitas presentasi guru cukup memadai untuk kelancaran belajar, penerangan umum di ruang kelas membantu membaca dan menulis, tayangan PPT yang dipresentasikan guru cukup jelas di baca, suhu udara di kelas cukup lancar sirkulasi udaranya, ruang kelas anda setiap hari masuk dirasakan bersih, warna dan ornamen ruang kelas cukup nyaman rasakan dalam belajar di kelas, ruang kelas cukup dialiri dengan listrik untuk kebutuhan belajar, di ruang kelas cukup di sediakan alat - alat peraga pelajaran, formasi tempat duduk di kelas membuat tidak jenuh, suasana tempat duduk berubah tiap saat lantai kelas cukup sehat, dapat dirasakan bebas dari serangga yang mungkin bisa mengganggu konsentrasi, penataan barang dan ornamen di kelas sudah cukup enak dipandang mata setiap hari, serta iklim yang nyaman akan menghilangkan kecanggungan siswa, baik sesama guru maupun antar siswa sendiri. Hal ini juga bisa mendorong siswa untuk mengajukan pertanyaan, sehingga komunikasi antara pendidik dan anak didik dapat terbangun.
\end{abstract}

Kata kunci: guru,siswa dan suasana kelas menyenangkan.

ABSTRACT

The purpose of this study was to determine the real conditions of learning in the classroom. The study was conducted at 23 schools consisting of high schools and vocational high schools in Balikpapan, the research being carried out was the School Action research. Real conditions that exist in high school and vocational schools in Balikpapan, seating facilities and desks in the classroom are enough to support you to learn, the area of your learning space is sufficient, so that free learning, teacher presentation facilities are adequate for smooth learning, public lighting in the room the class helps read and write, the PPT shows presented by the teacher are quite clear in reading, the air temperature in the class is quite smooth, the air circulation, your classrooms feel clean every day, the colors and ornaments of the classrooms are comfortable enough in learning in the classroom, the classrooms are sufficient electrified for learning needs, in the classroom enough provided teaching aids, the formation of seats in the classroom makes it unsaturated, the atmosphere of the seat changes every time the classroom floor is healthy enough, can be felt free of insects that might be able to disturb concentration, the arrangement of goods and ornaments in the classroom is quite pleasing to the eye every day, as well as advertising $m$ that is comfortable will eliminate the awkwardness of students, both fellow teachers and between students themselves. It can also encourage students to ask questions, so that communication between educators and students can be awakened.

Keywords: teacher, students and pleasant classroom atmosphere. 


\section{PENDAHULUAN}

Dalam rangka memperkuat posisi dan peran pendidikan nasional diperlukan upaya penataan pendidikan dalam berbagai aspek, sebab bila diadakan suatu perubahan pada aspek pendidikan maka pada bidang yang lain akan ada perubahan pula, pembentukan sikap yang baik diprioritaskan, oleh karena itu model pembelajaran yang sesuai untuk diterapkan pada kurikulum ini akan lebih bervariasi hal tersebut untuk mencari alternatif dalam upaya peningkatan mutu pendidikan, salah satunya melalui perubahan kurikulum, dengan penyempurnaan pola pikir secara berlandaskan nilai-nilai Pancasila, pendidikan harus sesuai dengan kebutuhan masa depan, dimana harus ada pergeseran atau perubahan pola pikir, salah satunya adalah dari berpusat pada guru harus berpusat pada peserta didik karena pendidikan sebagai faktor yang utama dalam pengembangan sumber daya manusia yang berlandaskan nilai Pancasila. Belajar sebagai sebuah proses.

Seorang guru yang memiliki kecenderungan dan bakat untuk menjadi guru, sehingga ia pun akan selalu memiliki sikap optimisme dalam pekerjaannya sebagai guru, ia akan cepat dan tepat dalam mengambil keputusan. Undang-Undang Nomor 14 Bab I Pasal 1 (2005 : 2). Di nyatakan bahwa : Guru adalah pendidik profesional dengan tugas utama mendidik, mengajar, membimbing, mengarahkan, melatih, menilai, dan mengevaluasi peserta didik pada pendidikan anak usia dini jalur pendidikan formal, pendidikan dasar, dan pendidikan menengah. Berdasarkan uraian di atas bahwa seorang guru memiliki posisi strategis dalam membina dan mengembangkan pembelajaran dengan Peserta didik di kelas maupun di luar kelas, oleh sebab itu guru harus memiliki kompetensi sebagai guru profesional yang sesuai pada bidang yang diajarkannya kepada peserta didik, agar proses pembelajaran berlangsung dengan baik dan hasilnya optimal, dan untuk mendisiplinkan peserta didiknya baik di sekolah maupun di lingkungannya. Guru sebagai pekerja harus berkemampuan yang meliputi penguasaan materi pelajaran, penguasaan profesional keguruan dan pendidikan, penguasaan cara-cara menyesuaikan diri dan berkepribadian untuk melaksanakan tugasnya, di samping itu guru harus merupakan pribadi yang berkembang dan bersifat dinamis.

Hal ini sesuai dengan yang tertuang dalam Undang-undang No. 20 tahun 2003 tentang Sistem Pendidikan Nasional bahwa : Pendidik dan tenaga kependidikan berkewajiban menciptakan suasana pendidikan yang bermakna, menyenangkan, kreatif, dinamis, dan dialogis, (2) mempunyai komitmen secara profesional untuk meningkatkan mutu pendidikan dan (3) memberi teladan dan menjaga nama baik lembaga, profesi, dan kedudukan sesuai dengan kepercayaan yang diberikan kepadanya.

Guru harus memiliki standar kualitas pribadi tertentu yang mencakup, tanggung jawab, wibawa, mandiri dan disiplin (Mulyasa, 2011: 37). Berdasar hal tersebut, guru sebagai pendidik menjadi tokoh panutan, dan identifikasi bagi para peserta didik lingkungannyaSemua orang yakin bahwa guru memiliki andil yang sangat besar terhadap keberhasilan pembelajaran di sekolah, guru adalah pendidik profesional yang mempunyai tugas, fungsi, dan peran penting dalam mencerdaskan kehidupan bangsa.

Guru yang profesional diharapkan mampu berpartisipasi dalam pembangunan nasional untuk mewujudkan insan Indonesia yang bertakwa kepada Tuhan YME, unggul 
dalam ilmu pengetahuan dan teknologi, memiliki jiwa estetis, etis, berbudi pekerti luhur, dan berkepribadian. Tidak lah berlebihan kalau dikatakan bahwa masa depan masyarakat, bangsa, dan negara, sebagian besar ditentukan oleh guru.

Sedangkan menurut Syaiful Sagala (2011:1) disebutkan bahwa: “ Seorang profesional mempunyai kebermaknaan ahli (expert) dengan pengetahuan yang dimiliki dalam melayani pekerjaannya". Berdasarkan pada pendapat tersebut, profesional mempunyai kebermaknaan ahli (expert) dengan pengetahuan yang dimiliki dalam melayani pekerjaannya. Guru merupakan figur yang ikut bertanggung jawab terhadap masa depan bangsa.

Menurut Endang Komara (2012:105). Dengan profesionalisme guru, maka guru masa depan tidak tampil lagi sebagai pengajar (teacher) seperti fungsinya yang menonjol selama ini tetapi beralih sebagai pelatih (coach), pembimbing (councelor) dan manajer belajar (learning manager). Berdasarkan pada pernyataan tersebut, jelas peran guru profesional menonjol sebagai pendidik dan membimbing dengan tugas utamanya merencanakan, melaksanakan dan mengevaluasi peserta didik terutama dalam menanamkan kedisiplinan bagi siswa sebab masa sekarang ini siswa di sekolah sudah mengabaikan rasa disiplin hal ini membuat khawatir orang tua juga guru.

Menurut Mulyasa (2011:36) Memanfaatkan waktu yang ada dan guru juga harus berpacu dalam pembelajaran, dengan memberikan kemudahan dalam belajar bagi peserta didik, agar dapat mengembangkan potensinya secara optimal.

Tujuan penelitian ini untuk mengetahui kondisi real pembelajaran dalam kelas, penelitian dilakukan pada 23 sekolah yang terdiri dari SMA dan SMK di Balikpapan, penelitian yang dilakukan yaitu penelitian Tindakan Sekolah.

\section{HASIL DAN PEMBAHASAN}

Dalam suatu kelas/ruangan, seorang guru sebenarnya mempunyai dua permasalahan pokok yaitu pengajaran dan manajemen dimana keduanya mempunyai penanganan sendiri. Pengajaran harus diatasi dengan cara pengajaran yang baik, sedangkan manajemen dengan cara pengelolaan. Aspek yang paling penting dalam proses belajar mengajar yaitu pengelolaan kelas dimana pengelolaan tersebut merupakan proses terjadinya tingkah laku yang kompleks dan seorang guru menggunakannya untuk menciptakan dan mempertahankan kondisi kelas secara efisien dan memungkinkan siswa dapat belajar dengan memperoleh rasa nyaman.

Pengelolaan kelas merupakan keterampilan guru untuk menciptakan dan mempertahankan kondisi proses belajar mengajar yang optimal. Namun, dalam pengelolaan kelas tidak menutup kemungkinan akan terjadi suatu permasalahan. (Suharsimi, 1996) menyebutkan bahwa sebab musabab masalah pengelolaan kelas yaitu :

1. Siswa tidak tahu apa yang harus diperbuat.

2. Siswa sudah diberi tahu akan tugasnya akan tetapi setelah beberapa lama kemudian mereka menjadi lupa akan tugasnya.

3. Siswa sudah mengetahui apa yang harus mereka diperbuat. Akan tetapi tidak tahu bagaimana cara melakukannya.

4. Ada beberapa siswa atau sebagian yang sudah melaksanakan tugas sebelum waktunya habis sehingga membuat keributan.

5. Ada diantara siswa yang merupakan anak malas tak bergairah atau pengganggu. Sehingga walaupun mereka melakukan tugas akan tetapi tidak secara sungguh-sungguh. 
Oleh karena itu penting bagi seorang guru untuk menguasai sebuah keterampilan, salah satunya keterampilan dalam mengelola kelas. Maka, dalam artikel ini penulis membahas tentang definisi keterampilan mengelola kelas, tujuan pengelolaan kelas, komponen keterampilan mengelola kelas, prinsip penggunaan keterampilan mengelola kelas dan keterampilan mengelola kelas yang baik, dengan tujuan untuk mendorong siswa dalam mengembangkan tanggung jawab individu maupun klasikal dalam berperilaku yang sesuai dengan tata tertib serta aktivitas yang sedang berlangsung, menyadari kebutuhan siswa, dan memberikan respon yang efektif terhadap perilaku siswa dengan tujuan supaya kondisi belajar yang optimal dapat tercapai dan guru mampu mengatur siswa dan sarana pengajaran serta mengendalikannya dalam suasana yang menyenangkan untuk mencapai tujuan pembelajaran.

(Depdikbud, 1985) menyatakan keterampilan mengelola kelas adalah keterampilan guru untuk menciptakan dan memelihara kondisi belajar yang optimal, dan keterampilan untuk mengembalikan kondisi belajar yang optimal, apabila terdapat gangguan dalam proses belajar baik yang bersifat gangguan kecil dan sementara maupun gangguan yang berkelanjutan. Menurut (Majid, 2014) pengelolaan kelas adalah keterampilan guru untuk menciptakan dan memelihara kondisi belajar yang optimal dan mengembalikannya jika terjadi gangguan dalam proses belajar mengajar. Menurut (Mulyasa, 2013) pengelolaan kelas merupakan keterampilan guru untuk menciptakan iklim pembelajaran yang kondusif, dan mengendalikannya jika terjadi gangguan dalam pembelajaran. Menurut (Usman, 2013) pengelolaan kelas adalah keterampilan guru untuk menciptakan dan memelihara kondisi belajar yang optimal dan mengembalikannya bila terjadi gangguan dalam proses belajar mengajar.

Menurut (Wardani, 2005) keterampilan mengelola kelas adalah keterampilan dalam menciptakan dan mempertahankan kondisi yang optimal guna terjadinya proses pembelajaran yang selalu serasi dan efektif.

Menurut (Wina Sanjaya, 2005) bahwa pengelolaan kelas merupakan keterampilan guru menciptakan dan memelihara kondisi belajar yang optimal dan mengembalikannya manakala terjadi hal-hal yang dapat mengganggu suasana pembelajaran.

Menurut (Winataputra, 2004) keterampilan mengelola kelas adalah keterampilan menciptakan dan memelihara kondisi belajar yang optimal, serta keterampilan guru untuk mengembalikan kondisi belajar yang terganggu ke arah kondisi belajar yang optimal.

Berdasarkan hasil penelitian Tindakan seolah ada 23 SMA dan SMK yang berada di Balikpapan, Kondisi real yang ada pada sekolah SMA dan SMK di Balikpapan, fasilitas tempat duduk dan meja di kelas sudah cukup menunjang anda untuk belajar, luas ruangan belajar anda cukup memadahi, sehingga leluasa belajar, fasilitas presentasi guru cukup memadahi untuk kelancaran belajar, penerangan umum di ruang kelas membantu membaca dan menulis, tayangan PPT yang dipresentasikan guru cukup jelas di baca, suhu udara di kelas cukup lancar sirkulasi udaranya, ruang kelas anda setiap hari masuk dirasakan bersih, warna dan ornamen ruang kelas cukup nyaman rasakan dalam belajar di kelas, ruang kelas cukup di aliri dengan listrik untuk kebutuhan belajar, di ruang kelas cukup di sediakan alat - alat peraga pelajaran, formasi tempat duduk di kelas membuat tidak jenuh, suasana tempat duduk berubah tiap saat, lantai kelas cukup sehat, dapat dirasakan 
bebas dari serangga yang mungkin bisa mengganggu konsentrasi, penataan barang dan ornamen di kelas sudah cukup enak dipandang mata setiap hari, Pada 23 SMK dan SMA di Balikpapan kondisi real pembelajaran dalam kelas sebanyak 71,47 hal ini menunjukkan baik untuk aspek suasana, serta 65,99 untuk rata-rata per sekolah, hal ini menunjukkan cukup baik walau belum signifikan perlu ditingkatkan kembali.

Data di atas dapat dilihat pada gambar 1.1 dan gambar 1.2 di bawah ini:

\begin{tabular}{|c|c|c|c|c|}
\hline \multicolumn{5}{|c|}{ KONDISI REAL KELAS PEMBELAJARAN } \\
\hline \multicolumn{3}{|c|}{$\begin{array}{l}\text { PRESENTASI SKOR TIAP } \\
\text { ASPEK }\end{array}$} & \multirow{2}{*}{$\begin{array}{l}\text { TOTAL } \\
\text { SKOR }\end{array}$} & \multirow{2}{*}{$\begin{array}{c}\text { RATA- } \\
\text { RATA } \\
\text { PER } \\
\text { SEKOLAH }\end{array}$} \\
\hline SISWA & GURU & SUASANA & & \\
\hline 46,67 & 60,00 & 64,00 & 170,67 & 56,89 \\
\hline 38,89 & 50,00 & 53,33 & 142,22 & 39,51 \\
\hline 60 & 80 & 80 & 220 & 73,33 \\
\hline 53,33 & 56,00 & 65,33 & 174,67 & 58,22 \\
\hline 66,67 & 75,56 & 68,89 & 211,11 & 70,37 \\
\hline 66,67 & 80,00 & 66,67 & 213,33 & 71,11 \\
\hline 46,67 & 60,00 & 73,33 & 180,00 & 60,00 \\
\hline 70,00 & 53,33 & 56,67 & 180,00 & 60,00 \\
\hline 65,00 & 66,67 & 83,33 & 215,00 & 71,67 \\
\hline 46,67 & 53,33 & 60,00 & 160,00 & 53,33 \\
\hline 52,50 & 75,83 & 52,50 & 180,83 & 60,28 \\
\hline 51,11 & 88,89 & 88,89 & 228,89 & 76,30 \\
\hline 58,52 & 54,07 & 65,93 & 178,52 & 44,08 \\
\hline 65,00 & 83,33 & 78,33 & 226,67 & 75,56 \\
\hline 73,33 & 66,67 & 90,00 & 230,00 & 76,67 \\
\hline 65,00 & 73,33 & 63,33 & 201,67 & 67,22 \\
\hline 68,89 & 84,44 & 80,00 & 233,33 & 77,78 \\
\hline 61,67 & 80,00 & 83,33 & 225,00 & 75,00 \\
\hline 51,67 & 71,67 & 70,00 & 193,33 & 64,44 \\
\hline 63,33 & 93,33 & 83,33 & 240,00 & 80,00 \\
\hline 40,00 & 73,33 & 86,67 & 200,00 & 66,67 \\
\hline 51,67 & 66,67 & 70,00 & 188,33 & 62,78 \\
\hline 46,67 & 53,33 & 60,00 & 160,00 & 53,33 \\
\hline & & 71,47 & & \\
\hline
\end{tabular}

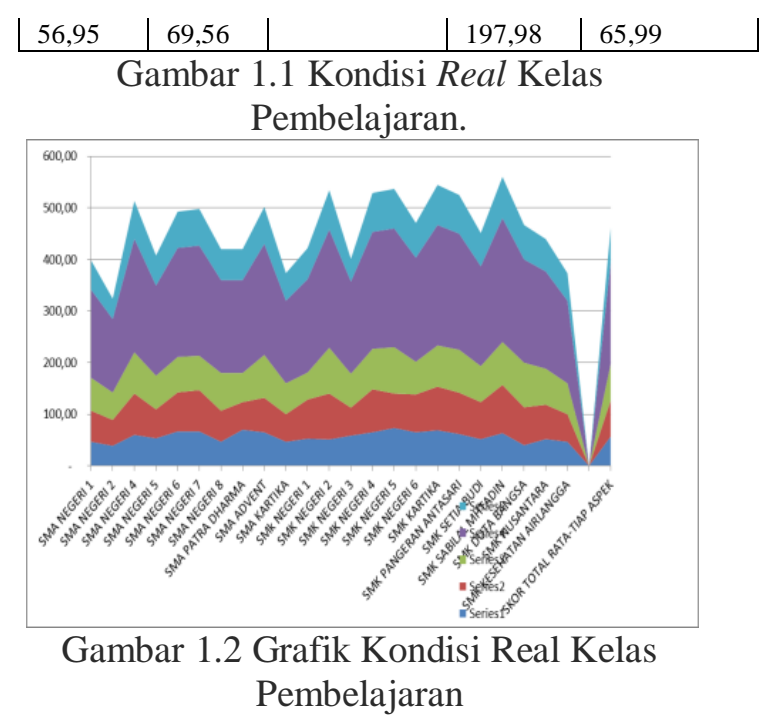

\section{KESIMPULAN DAN SARAN}

Tujuan pengelolaan kelas adalah menyediakan dan menggunakan fasilitas belajar untuk bermacammacam kegiatan belajar mengajar agar mencapai hasil yang baik. Mengembangkan kemampuan siswa dalam menggunakan alat-alat belajar, menyediakan kondisi-kondisi yang memungkinkan siswa bekerja dan belajar, serta membantu siswa untuk memperoleh hasil yang diharapkan.

Keterampilan mengelola kelas merupakan keterampilan yang digunakan oleh seorang guru dalam proses pembelajaran guna untuk mengkondisikan belajar siswa dengan harapan supaya terjadi suatu kondisi kelas yang kondusif, memaksimalkan sarana dan prasarana, menjaga keterlibatan siswa, menciptakan dan mempertahankan kondisi belajar yang optimal dan rasa nyaman dalam proses belajar mengajar. Kondisi real yang ada pada sekolah SMA dan SMK di Balikpapan, fasilitas tempat duduk dan meja di kelas sudah cukup menunjang anda untuk belajar, luas ruangan belajar anda cukup memadahi, sehingga leluasa belajar, fasilitas presentasi guru cukup memadahi untuk kelancaran belajar, penerangan umum di ruang kelas membantu membaca dan menulis, tayangan PPT yang dipresentasikan guru cukup jelas di baca, suhu udara di 
kelas cukup lancar sirkulasi udaranya, ruang kelas anda setiap hari masuk dirasakan bersih, warna dan ornamen ruang kelas cukup nyaman rasakan dalam belajar di kelas, ruang kelas cukup di aliri dengan listrik untuk kebutuhan belajar, di ruang kelas cukup di sediakan alat -alat peraga pelajaran, formasi tempa duduk di kelas membuat tidak jenuh, suasana tempat duduk berubah tiap saat lantai kelas cukup sehat, dapat dirasakan bebas dari serangga yang mungkin bisa mengganggu konsentrasi, penataan barang dan ornamen di kelas sudah cukup enak dipandang mata setiap hari,

Kepada guru dalam melaksanakan keterampilan mengelola kelas, perlu memperhatikan komponen keterampilan yang berhubungan dengan penciptaan dan pemeliharaan kondisi belajar yang optimal. Setiap guru, baik itu guru kelas maupun guru bidang studi, secara langsung pasti terlibat dalam kegiatan pengelolaan. Lebih tepatnya dalam pengelolaan kelas. Hal ini berkaitan dengan kemampuan seorang guru dalam mengambil inisiatif dan mengendalikan pelajaran. Tujuannya adalah agar proses pembelajaran itu sendiri dapat berjalan efektif dan efisien, sehingga kompetensi yang diharapkan mampu dikuasai oleh siswa dan dapat tercapai.

\section{DAFTAR PUSTAKA}

Majid, Abdul. (2014). Belajar dan Pembelajaran. Bandung: PT REMAJA ROSDAKARYA.

Entang, T raka Joni an Prayitno. (1985). Pengelolaan Kelas, Proyek Pengembangan Lembaga Pendidikan Tenaga Kependidikan. Jakarta: Dirjen Dikti Depdikbud.

Mulyasa, E. (2013). Menjadi Guru Profesional. Bandung: PT REMAJA ROSDAKARYA.

Wina Sanjaya. (2005). Pembelajaran dalam Implementasi Kurikulum
Berbasis Kompetensi. Jakarta: Kencana Prenada Media Grup.

Winataputra, Udin. S. (2004). Strategi

Belajar Mengajar. Jakarta:

Universitas Terbuka.

Komara, Endang. (2002). Penelitian

Tindakan Kelas dan

Peningkatan Profesionalitas

Guru. Bandung : revika Aditama

Mulyasa. (2011). Menjadi Guru Profesional. Bandung : Rosdakarya.

Sagala, Syaiful. (2011). Kemampuan Profesional Guru dan Tenaga Kependidikan. Bandung: Alfabeta.

Undang- Undang Nomor 20 Tahun 2003. Tentang Sistem Pendidikan Nasional : Jakarta.

Undang- Undang Nomor 14 Tahun 2005. Tentang Guru dan Dosen. Bab I Pasal 1 